\title{
A Case of Alopecia with Acute Pigment-Loss
}

\section{T.J.}

\author{
Damsté
}

\section{Amsterdam}

Author's address: Th. J. Damsté, M. D., Department of Dermatology, Binnengasthuis, Amsterdam-C (The Netherlands) A 42-year-old man, a pronounced dark type, had after having lost tufts of hair, turned snowwhite in some weeks. On closer inspection it appeared that he still had some dark hairs, that were however lying loose on his skull. His eyelashes were still present, the eyebrows and beard hairs had almost completely disappeared. The arm-pit, pubis and body hair was normal, also the nails. He made a perfectly healthy impression, had not been ill during the last six months, had not used any medicaments, had not been in touch with poisons, had not gone through a psychical trauma and was a cheerful person. WaR and VDRL-reactions neg., Hb, blood-picture, sedimentationrate and urine showed no deviations.

A month later the eyelashes had also fallen out; after three months the eyelashes and eyebrows had grown again and some months after that the hair looked fuller and it appeared to develop pigment again. These new hairs were about $6 \mathrm{~cm}$ long, with a $2 \mathrm{~cm}$ long white end, $1 \mathrm{~cm}$ grey middle and a $3 \mathrm{~cm}$ long dark root, from which one might conclude that the hair had been growing for 4 or 5 months and that the forming of pigment restored itself three months previously.

A year after the beginning of the falling out of the hair he again had a thick dark mop of hair with some grayish stripes, while the eyebrows, eyelashes and beard had returned completely to the original colour.

Summary

To summarize, it concerned a man, 42 years of age, who showed a total falling out of hair, of the pigmented hairs of the head and the face, while the previous almost invisible white hairs did not fall out, it made one think that he had turned white within a short time.

For this falling out of hair no cause was found. This case is presumably allied to alopecia areata. This form of hair loss might explain the cases of "suddenly turning white". 